\title{
FAKTOR-FAKTOR YANG MEMPENGARUHI HIPERTENSI PADA LANSIA DI WILAYAH KERJA PUSKESMAS DAIK TAHUN 2020 Hazlini
}

Program Studi Ilmu Keperawatan

Sekolah Tinggi Ilmu Kesehatan Awal Bros Batam

Email korespondensi : hazlini123@gmail.com

\begin{abstract}
ABSTRAK
Proses penuaan merupakan proses perubahan yang dialami individu dan proses ini akan diikuti penurunan fungsi fisiologis, kognitif, dan psikososial. Hipertensi atau tekanan darah tinggi adalah suatu kondisi peningkatan abnormal tekanan darah dalam pembuluh darah arteri. Hipertensi terjadi akibat peningkatan curah jantung atau dikarenakan peningkatan resistensi vaskuler karena efek vasokontriksi yang melebihi efek vasodilatasi (Syamsudin, 2011). Perevalensi hipertensi meningkat sejalan dengan perkembangan gaya hidup, merokok, obesitas, konsumsi alcohol, tipe keperibadian dan stress. Studi pendahuluan yang telah dilakukan peneliti untuk mendapatkan data awal penderita hipertensi primer di Puskesmas Daik, didapatkan jumlah kunjungan 1 tahun terakhir dari bulan januari-desember 2019 sebanyak 208 pasien hipertensi primer. Wawancara dilakukan kepada 10 orang, yang terdiri dari 3 orang pre-hipertensi dengan gejala kadang-kadang mudah merasa kesal karena obesitas, 4 orang hipertensi derajat I karena di rumah sering mengkonsumsi garam dan makanan laut, dan 3 orang hipertensi derajat II dengan gejala mudah marah, mudah tersinggung dan sulit untuk bernafas ketika sedang marah. Penelitian ini bertujuan untuk mengetahui faktor-faktor yang mempengaruhi hipertensi pada lansia di wilayah Puskesmas Daik 2020. Penelitian ini menggunakan desain analitik observasional, dengan pendekatan waktu cross sectional. Uji statistik dengan menggunakan Chi-Square. Sampel pada penelitian ini sebanyak 51 lansia. Teknik sampling yang digunakan purposive sampling. Alat ukur yang digunakan adalah kuisioner aktivitas fisik dan diit. Berdasarkan penelitian diperoleh data mengenai aktivitas fisik menunjukkan aktivitas aktif sebanyak 21 lansia (41,2\%) dan aktivitas tidak aktif 30 lansia $(58,8 \%)$. Diit garam sebagian besar lansia tinggi sebanyak 34 lansia (67,7\%) dan diit rendah garam 17 lansia (33,3\%). Hasil uji Chi-Square didapatkan pvalue sebesar 0,000<0,05. Ada hubungan antara aktivitas fisik dan diit garam dengan kejadian hipertensi pada lansia.
\end{abstract}

Kata kunci : Hipertensi; aktivitas fisik; diit garam. 


\title{
FACTORS THAT AFFECTING HYPERTENSION ON ELDERLY IN PUBLIC HEALTH CENTRE AREA OF DAIK IN 2020
}

\begin{abstract}
The aging process is a process of change experienced by individuals and this process will be followed by a decline in physiological, cognitive, and psychosocial functions. Hypertension or high blood pressure is a condition of an abnormal increase in blood pressure in the arteries. Hypertension occurs due to increasing cardiac output or increasing vascular resistance because of vasoconstriction effects that exceeds vasodilation effects (Syamsudin, 2011). The prevalence of hypertension increases with the development of lifestyle, smoking, obesity, alcohol consumption, personality types and stress. The prevoious study that researcher have conducted to get initial data on primary hypertension sufferers at Daik Health Center obtained the number of visits in the last year from January to December 2019 as many as 208 primary hypertension patients. Interview were conducted with 10 people thhat consist of 3 people with pre-hypertension which the symptoms was sometimes easily irritated by obesity, 4 people with grade I hypertension because they often consume salt and seafood at home, and 3 people with grade II hypertension with irritability. , irritable and difficult to breathe when angry. This study aims to determine the factors that influence hypertension in the elderly in the area of Daik Health Center 2020. This study used an observational analytic design, with a cross sectional time approach. Statistical test using Chi-Square. The sample in this study were 51 elderly. The sampling technique used purposive sampling. To measuring instrument researcher used a physical activity questionnaire and diet. Based on the study, data on physical activity showed active activity as many as 21 elderly (41.2\%) and inactive activity by 30 elderly (58.8\%). Most of the elderly have high salt diet as many as 34 elderly (67.7\%) and 17 elderly people with low salt diet (33.3\%). Chi-Square test results obtained p-value of $0.000<0.05$. There is a relationship between physical activity and dietary salt with the incidence of hypertension in the elderly.
\end{abstract}

Key words: Hypertension; physical activity; diet salt. 


\section{PENDAHULUAN}

Undang-undang Nomor 13 Tahun 1998 Bab 1 pasal 1 ayat 2 tentang kesejahteraan lansia mengatakan bahwa lansia adalah seseorang yang sudah berusia 60 tahun ke atas. Badan Pusat Statistik menyatakan, data dari sensus penduduk 2015 jumlah lanjut usia di Indonesia yaitu 21,69 juta jiwa dari total seluruh penduduk Indonesia 258,70 juta jiwa dan diperkirakan pada tahun 2035 lansia akan meningkat menjadi 48,20 juta jiwa. Peningkatan populasi lansia dan juga dengan bertambahnya umur, fungsi tubuh lansia mengalami penurunan akibat penuaan sehingga banyak permasalahan kesehatan muncul (Kemenkes, 2016).

Ashar (2016) mengungkapkan penurunan fungsi fisiologis lansia di Panti Werdha Margaguna didapatkan hasil pada sistem kardiovaskuler, lansia yang memiliki gangguan jantung sebanyak $27(71,1 \%)$ dan 11 yang tidak memiliki gangguan jantung 11(28\%). Pada sistem muskuloskletal, lansia yang mengalami gangguan anggota gerak sebanyak 19 (50\%) sedangkan yang tidak memiliki gangguan 19 (50\%). Pada sistem saraf, lansia yang mengalami gangguan pada sistem saraf sebanyak $26(68,4 \%)$ dan yang tidak memiki gangguan sebanyak 12 (31,6\%). Beberapa masalah diatas akan menyebabkan lansia mengalami berbagai permasalahan pada proses penuaan salah satunya adalah hipertensi.

Hipertensi atau tekanan darah tinggi adalah "suatu kondisi peningkatan abnormal tekanan darah dalam pembuluh darah arteri secara terus-menerus dalam satu periode. Hal ini terjadi apabila arteriol-arteriol kontriksi dan membuat darah sulit mengalir dan meningkatkan tekanan darah melawan kearah dinding arteri" (Udjianti,2010). "Tekanan darah sistole $140 \mathrm{mmHg}$ atau lebih dan tekanan darah diastole $90 \mathrm{mmHg}$ atau lebih. Hipertensi terjadi akibat peningkatan curah jantung atau dikarenakan peningkatan resistensi vaskuler karena efek vasokontriksi yang melebihi efek vasodilatasi" (Syamsudin, 2011).
Penelitian Seke (2016) menyebutkan, "terdapat hubungan yang signifikan antara kejadian stres dengan penyakit hipertensi pada lansia dengan menggunakan Fisher's Exact Test $(p=0,000)$. Faktor genetik mempengaruhi kepekaan terhadap sodium, kepekaan terhadap stres, reaktivitas pembuluh darah terhadap vasokontriktor, resistansi insulin dan lain-lain. Pada faktor lingkungan antara lain diet, kebiasaan merokok, stres emosi, obesitas dan lain-lain" (Syamsudin, 2011).

"Kondisi tekanan darah tinggi yang terusmenerus dapat menyebabkan jantung seseorang bekerja lebih keras, kondisi ini akan mengakibatkan terjadinya kerusakan pada pembuluh darah, jantung, ginjal, otak, dan mata" (Sugiyono, 2009).

Penelitian Rihiantoro \& Widodo (2017) menyatakan "diperoleh nilai $\rho$-value $=0,000$. Hal ini menunjukan adanya hubungan pola makan dengan kejadian hipertensi. Hasil analisis juga menggambarkan nilai $\mathrm{OR}=4.31 \quad 92,187-8,494$ ) yang berarti pola makan yang buruk berisiko untuk menderita hipertensi 4,31 kali dibandingkan pola makan yang baik. Hasil penelitian ini menunjukkan bahwa hasil analisis regresi logistic berganda terlihat nilai OR Exp (B) asupan natrium sebesar 4,627 bahwa asupan natrium berlebih memiliki risiko 4,627 mengalami kejadian hipertensi”.

Studi pendahuluan yang telah dilakukan peneliti untuk mendapatkan data awal penderita hipertensi primer di Puskesmas Daik, didapatkan jumlah kunjungan 1 tahun terakhir dari bulan januari-desember 2019 sebanyak 208 pasien hipertensi primer. Wawancara dilakukan kepada 10 orang, yang terdiri dari 3 orang prehipertensi dengan gejala kadang-kadang mudah merasa kesal karena obesitas, 4 orang hipertensi derajat I karena di rumah sering mengkonsumsi garam dan makanan laut, dan 3 orang hipertensi derajat II dengan gejala mudah marah, mudah tersinggung dan sulit untuk bernafas ketika sedang marah. Stressor yang didapatkan biasanya karena pekerjaan dan juga masalah rumah tangga. 
Berdasarkan uraian diatas peneliti tertarik untuk mengadakan penelitian mengenai faktor-faktor yang mempengaruhi hipertensi

\section{METODE PENELITIAN}

Penelitian ini merupakan jenis penelitian analitik observasional dengan pendekatan potong silang (cross sectional) Handayani \& Riyadi, 2015). Lokasi penelitian di Puskesmas Daik. Pengambilan data dilakukan pada JanuariFebruari 2020 dengan teknik purposive sampling sebanyak 51 responden.

Variabel dalam penelitian ini adalah "faktor-faktor yang mempengaruhi hipertensi. pada lansia di wilayah kerja Puskesmas Daik Tahun

2020.

Alat pengumpulan data yang digunakan adalah untuk mengetahui riwayat hipertensi, pola aktivitas fisik dan diit yang tidak sehat. Kuesioner yang digunakan sudah dilakukan uji validitas dan reliabelitas sehingga tidak dilakukan uji validitas dan reliabelitas ulang. Data yang sudah terkumpul kemudian dilakukan editing, coding, prosessing dan cleaning data. Analisis data yang digunakan yaitu analisis univariat dan bivariat" (Dharma, 2011).

\section{HASIL DAN PEMBAHASAN}

1. Analisa Univariat

\section{Tabel 4.1}

Karakteristik Responden Hipertensi Berdasarkan Usia, Jenis Kelamin, Pendidikan Terakhir, Pekerjaan dan status Hipertensi Di Puskesmas Daik Tahun 2020

\begin{tabular}{|c|c|c|c|}
\hline No. & $\begin{array}{c}\text { Karakteristik } \\
\text { Responden }\end{array}$ & $\begin{array}{c}\text { Frekuensi } \\
\text { (n) }\end{array}$ & Persentase (\%) \\
\hline 1 & Usia & & \\
\hline . & a. $60-74$ tahun & 42 & 82,4 \\
\hline & b. $75-90$ tahun & 9 & 17,6 \\
\hline 2. & Jenis Kelamin & & \\
\hline & a. Laki-laki & 14 & 27,5 \\
\hline & b. Wanita & 37 & 72,5 \\
\hline 3. & Pendidikan Terakhir & & \\
\hline & a. Tidak sekolah & 32 & 62,7 \\
\hline & b. SD & 16 & 31,4 \\
\hline & c. SMP & 1 & 2,0 \\
\hline & d. SMA & 2 & 3,9 \\
\hline 4. & Pekerjaan & & \\
\hline & a. Tidak berkerja & 39 & 76,5 \\
\hline & b. Nelayan & 2 & 3,9 \\
\hline & c. Buruh & 7 & 13,7 \\
\hline & d. Petani & 4 & 5,9 \\
\hline 5. & Status hipertensi & & \\
\hline & a. Hipertensi & 34 & 66,7 \\
\hline & b. Tidak hipertensi & 17 & 33,3 \\
\hline
\end{tabular}

Berdasarkan Tabel 4.1 dapat dilihat bahwa
karateristik responden menurut usia sebagian responden $(82,4 \%)$, mayoritas berjenis kelamin
perempuan sebanyak 37 responden $(72,5 \%)$, 
sebagian besar tidak sekolah sebanyak 32 respoden $(62,7 \%)$, tidak bekerja sebanyak 39 responden $(76,5 \%)$ dan yang memiliki status hipertensi sebanyak 34 responden $(66,7 \%)$.

\section{Analisa Bivariat}

Hasil Uji Hubungan Aktivitas fisik dengan hipertensi sebagai berikut :

Tabel 4.4 Uji Tabulasi Silang Hubungan Aktivitas Fisik Dengan Hipertensi

\begin{tabular}{|c|c|c|c|c|c|c|c|}
\hline \multirow{3}{*}{$\begin{array}{l}\text { Aktivitas } \\
\text { fisik }\end{array}$} & \multicolumn{7}{|c|}{ Status Hipertensi } \\
\hline & \multicolumn{2}{|c|}{ Hipertensi } & \multicolumn{2}{|c|}{$\begin{array}{l}\text { Tidak } \\
\text { hipertensi }\end{array}$} & \multicolumn{2}{|c|}{ Total } & $p$-Value \\
\hline & $\begin{array}{l}(\mathrm{n} \\
)^{2}\end{array}$ & $(\%)$ & (n) & $(\%)$ & & $\begin{array}{l}(\% \\
)\end{array}$ & \multirow[t]{3}{*}{0,000} \\
\hline Aktif & 6 & 11,8 & 15 & 29,4 & 21 & $\begin{array}{l}41, \\
2\end{array}$ & \\
\hline Tidak aktif & 28 & 54,9 & 2 & 3,9 & 30 & $\begin{array}{l}58, \\
8\end{array}$ & \\
\hline Total & 34 & 66,7 & 17 & 33,3 & 51 & $\begin{array}{l}10 \\
0\end{array}$ & \\
\hline
\end{tabular}

Berdasarkan tabel 4.4 menunjukkan responden yang aktif beraktifitas fisik lebih banyak tidak menderita hipertensi, sedangkan responden yang tidak aktif melakukan aktifitas fisik sebagian bersar menderita hipertensi. Hasil uji statistic menggunakan chi squere diketahui bahwa nilai $p$ value $0,000<0,05$. Maka dapat disimpulkan bahwa ada hubungan antara aktivitas fisik dengan kejadian hipertensi pada lansia.

"Aktivitas fisik, seperti olahraga, dapat mengurangi tekanan darah bukan hanya disebabkan berkurangnya berat badan, tetapi juga disebabkan bagaimana tekanan darah dihasilkan. Tekanan darah ditentukan oleh dua hal, yaitu jumlah darah yang dipompakan jantung per detik dan hambatan yang dihadapi darah dalam melakukan tugasnya melalui arteri. Olahraga dapat menyebabkan pertumbuhan pembuluh darah kapiler yang baru dan jalan darah yang baru. Hal yang dapat menghambat pengaliran darah dapat dikurangi, yang berarti mengurangi tekanan darah" (Abdurrachim dkk, 2016).

Hasil Uji hubungan Diit Garam dengan hipertensi sebagai berikut :

Tabel 4.5 Uji Tabulasi Silang Hubungan Diit Garam Dengan Hipertensi

\begin{tabular}{|c|c|c|c|c|c|c|c|}
\hline \multirow[t]{3}{*}{ Diit garam } & \multicolumn{7}{|c|}{ Status Hipertensi } \\
\hline & \multicolumn{2}{|c|}{ Hipertensi } & \multicolumn{2}{|c|}{ Tidak hipertensi } & \multicolumn{2}{|c|}{ Total } & \multirow[t]{2}{*}{$p$-Value } \\
\hline & (n) & $(\%)$ & (n) & $(\%)$ & (n) & $(\%)$ & \\
\hline $\begin{array}{l}\text { Rendah } \\
\text { garam }\end{array}$ & 3 & 5,9 & 14 & 27,5 & 17 & 33,3 & \multirow[t]{3}{*}{0,000} \\
\hline Tinggi garam & 31 & $\begin{array}{l}60, \\
8\end{array}$ & 3 & 5,9 & 34 & 66,7 & \\
\hline Total & 34 & $\begin{array}{l}\text { 66, } \\
7\end{array}$ & 17 & 33,3 & 51 & 100 & \\
\hline
\end{tabular}


menggunakan chi squere diketahui bahwa nilai $p$ value $0,000<0,05$, artinya bahwa ada hubungan antara diit garam dengan kejadian hipertensi pada lansia.

bertujuan untuk menghilangkan retensi garam dalam tubuh. Dasar diit hipertensi yang perlu diperhatikan adalah membatasi penggunaan garam natrium serta jenis makanan berlemak" (Abdurrachim, 2015). "Natrium diabsorpsi di usus halus secara aktif (membutuhkan energi), lalu dibawa oleh aliran darah ke ginjal untuk disaring kemudian dikembalikan ke aliran darah dalam jumlah cukup untuk mempertahankan taraf natrium dalam darah. Kelebihan natrium akan dikeluarkan melalui urine yang diatur oleh hormon aldosteron yang dikeluarkan oleh kelenjar adrenal jika kadar natrium darah menurun" Hartono dalam (Adbdurrachim dkk 2016).

\section{PEMBAHASAN}

\section{Hubungan aktivitas fisik dengan hipertensi}

Berdasarkan hasil penelitian menunjukkan bahwa responden yang aktif beraktifitas fisik lebih banyak tidak menderita hipertensi, sedangkan responden yang tidak aktif melakukan aktifitas fisik sebagian besar menderita hipertensi. Hasil uji statistic menggunakan chi squere diketahui bahwa nilai $p$ value $0,000<0,05$. Maka dapat disimpulkan bahwa ada hubungan antara aktivitas fisik dengan kejadian hipertensi pada lansia. Semakin aktif aktifitas fisiknya semakin normal tekanan darah, dan semakin tidak aktif aktifitas fisiknya semakin tinggi tekanan darah.

Hasil penelitian menunjukkan sebagian besar lansia tidak aktif beraktivitas atau hanya berdiam diri saja dirumahnya. Hal ini dikarenakan sebagian besar respoden sudah tidek bekerja, sehingga tidak ada aktivitas secara rutin dalam melakukan aktivitas fisik. Aktivitas fisik yang baik dan rutin akan melatih otot jantung dan tahanan perifer yang
"Diit rendah garam membantu menurunkan tekanan darah tinggi serta mempertahankan tekanan darah menuju normal. Selain itu

dapat mencegah peningkatan tekanan darah. Olahraga yang teratur dapat merangsang pelepasan hormon endorfin yang menimbulkan efek euphoria dan relaksasi otot sehingga tekanan darah tidak meningkat (Kokkinos et $a l, 2009)$. "Aktivitas fisik yang dianjurkan untuk usia 18-64 tahun adalah seperti berjalan, bersepeda, bermain games, olahraga (aerobik), membersihkan rumah, berkebun dan lainnya. Olahraga dapat mengurangi tekanan darah bukan hanya dapat mengurangi berat badan, tetapi juga karena olahraga dapat menyebabkan pertumbuhan pembuluh darah kapiler yang baru dan jalan darah yang baru, sehingga dapat menghindari atau mengurangi penghambatan pengaliran darah" (Harahap, 2017).

\section{Hubungan diit garam dengan hipertensi}

Berdasarkan hasil penelitian menunjukkan bahwa responden yang diit garam rendah lebih banyak tidak menderita hipertensi, sedangkan responden yang diit garam tinggi sebagian besar menderita hipertensi. Hasil uji statistic menggunakan chi squere diketahui bahwa nilai $p$ value $0,000<0,05$, artinya bahwa ada hubungan antara diit garam dengan kejadian hipertensi pada lansia. Artinya lansia yang mengkonsumsi tinggi garam berisiko untuk menderita hipertensi. Hal ini sejalan dengan penelitian yang dilakukan oleh Mahmudah dkk, (2015) menunjukkan "adanya hubungan antra konsumsi tinggi natrium dengan hipertensi yaitu nilai $(p=0,001<0,05)$. Hasil penelitian ini sesuai dengan pernyataan Susanto (2010) menyatakan bahwa konsumsi natrium yang berlebih akan meningkatkan ekstraseluler dan cara untuk menormalkannya cairan intraseluler ditarik keluar sehingga volume cairan ekstraseluler meningkat dan akibat dari meningkatnya 
volume cairan ekstraseluler tersebut menyebabkan meningkatnya volume darah yang berdampak pada timbulnya hipertensi. Sedangkan mengkonsumsi rendah garam dapat mempertahankan tekananan darah menuju normal".

"Diit rendah garam membantu menurunkan tekanan darah tinggi serta mempertahankan tekanan darah menuju normal. Selain itu, bertujuan untuk menghilangkan retensi garam dalam tubuh. Dasar diit hipertensi yang perlu diperhatikan adalah membatasi penggunaan garam natrium serta jenis makanan berlemak" (Abdurrachim, 2015). "Fungsi natrium dalam tubuh ialah menjaga keseimbangan cairan dan asam basa tubuh, namun apabila asupan natrium berlebihan dapat menyebabkan ketidakseimbangan cairan tubuh sehingga menimbulkan penimbunan cairan (edema)" (Pratiwi, 2015).

\section{SIMPULAN}

1. Terdapat hubungan aktivitas fisik dengan hipertensi pada lansia di Puskesmas Daik Kecamatan Lingga Kabupaten Lingga dengan nilai $p$ value 0,000

2. Terdapat hubungan diit garam dengan hipertensi pada lansia di Puskesmas Daik Kecamatan Lingga Kabupaten Lingga $p$ value 0,000

\section{UCAPAN TERIMAKASIH}

1. Bapak Prof. Dr. Fadil Oenzil, PhD.Sp.Gk selaku Ketua Stikes Awal Bros Batam.

2. Ibu Ns. Sri Muharni, S.Kep, M.Kep selaku Ketua Prodi Ilmu Keperawatan Stikes Awal Bros Batam.

3. Ibu Mira Agusthia, Ners, M.Kep, selaku pembimbing I.

4. Ibu Rachmawaty M. Noer, Ners. M.Kep, selaku Pembimbing II.

5. Bapak dr. Roni, Selaku Kepala Puskesmas Daik Kecamatan Lingga Kabupaten Lingga.

6. Seluruh Dosen dan staf pengajar yang sudah mendukung proses penyusunan Skripsi ini dari awal sampai akhir.
7. Seluruh Mahasisawa Sarjana Keperawatan Angkatan XI Stikes Awal Bros Batam.

\section{DAFTAR PUSTAKA}

Abdurrachim, R., Indah, H.,Nany, S. 2016. Hubungan Asupan Natrium, Frekuensi Dan Durasi Aktivitas Fisik Terhadap Tekanan Darah Lansia Di Panti Sosial Tresna Werdha Budi Sejahtera Dan Bina Laras Budi Luhur Kota Banjarbaru, Kalimantan Selatan. Journal of the Indonesian Nutrition Association 2016, 39(1):37-48

Ashar, P.H. 2016., Gambaran Persepsi Faktor Risiko Jatuh Pada Lansia di Panti Werdha Budi Mulia 4 Margaguna Jakarta Selatan. Repository UINJKT. Diperleh dari <http://repository.uinjkt.ac.id/dspace/bitstre am/123456789/37371/1/PERMATA\%20HI DAYAT\%20ASHAR\%20-\%20FKIK.pdf> [Diakses pada tanggal 20 Maret 2020 pukul 20:00 wib].

Atun,T., Siswati, T., Kurdanti, W., 2014. Asupan Sumber Natrium, Rasio Kalium, Aktivitas Fiisk dan Tekanan Darah Pasien Hipertensi. Yogyakarta: Politekhnik Kemenkes Yogyakarta. Azizah, L.M., 2011. Keperawatan lanjut usia. Yogyakarta: Graha Ilmu.

Azizah, L.M., 2011. Keperawatan lanjut usia. Yogyakarta: Graha Ilmu.

Burnner \& Suddarth., 2013. Keperawatan Medikal Bedah. Ed. 12. Jakarta: EGC

Cahyono S. 2008. Gaya Hidup dan Penyakit Modern. Jakarta: Kanisius.

Dahlan, S., 2010. Besar Sampel dan Cara Pengambilan Sampel dalam Penelitiian Kedokteran dan Kesehatan, Jakarta: Slemaba Medika.

Elisabeth, C.J., 2009. Buku Saku Patofisiologi. Penerbit Buku kedokteran EGC: Jakarta.Hartono A. (2006). Terapi Gizi dan Diet. Edisi 2. Jakarta: EGC.

Harahap, R.A., dkk. 2017. Pengaruh Aktivitas Fisik Terhadap Kejadian Hipertensi di Wilayah Puksesmas Bromo Medan Tahun 2017. Jurnal Muara Sains. Vol 1(2). 
Diperoleh

dari

https://www.google.com/search?q=PENGA

RUH+AKTIVITAS+FISIK+TERHADAP+

KEJADIAN+HIPERTENSI+PADA+LAKI

-LAKI+DEWASA+AWAL+\%2818-

40+TAHUN\%29+DI+WILAYAH+PUSKE

SMAS+BROMO+MEDAN+TAHUN+201

$7 \&$ ie $=$ utf $-8 \&$ oe $=$ utf $-8 \&$ client $=$ firefox $-\mathrm{b}$

[Diakses pada 24 Januari 2020].

Maryam, R.S., Ekasari, M.F., Rosidawati,

Jubaedi, A., 2008. Mengenal usia lanjut dan perawatannya. Jakarta : Salemba Medika.

Notoatmodjo, S., 2010. Metodelogi Penelitian Kesehatan, Jakarta: Rineka Cipta.

\section{Metodelogi Penelitian} Kesehatan, Edisi Revisi Cetakan Ke-2, Jakarta: Rineka Cipta.

Nugroho, W., 2012. Keperawatan gerontik dan geriatrik. Jakarta:EGC

Pratiwi, I.E. (2015). Penatalaksanaan Makanan Diet Rendah Garam Di Unit Dapur Pasien Instalasi Gizi Rumah Sakit PHC Surabaya. Jurnal Universitas Surabaya. 2015; Vol 3(3): 132

Stockslager, J.L \& Schaeffer. L., 2008. Asuhan keperawatan Geriatrik. Edisi 2.

Rawasiah, A.B. (2014). Hubungan Faktor Konsumsi Makanan Dengan Kejadian Hipertensi Pada Lansia Di Puskesmas PattinggalloangMakassar.

Kementrian Kesehatan Republik Indonesia., 2016. Situasi dan analisis lanjut usia di Indonesia. Jakarta: Kementerian Kesehatan Republik Indonesia. Diperoleh dari <http://www.depkes.go.id/article/view/1401 0200005/download-pusdatin-infodatininfodatin-lansia.html $\geq \quad$ [Diakses pada tanggal 8 Maret 2020].

Seke, P. A., Bidjuni, H., \& Lolong, J., 2016. Hubungan Kejadian Stres Dengan Penyakit Hipertensi Pada Lansia Di Balai Penyantunan Lanjut Usia Senjah Cerah Kecamatan Mapang Kota Manado. Jurnal Keperawatan, 4(2).
Syamsudin., 2011. Buku Ajar Farmakologi Kardiovaskuler dan Renal. Jakarta: Salemba Medika

Sigarlaki, Herke. J. O.,2006. Karakteristik dan Faktor Berhubungan Dengan Hipertensi di Desa Bocor,kecamatan Bulus Pesantren Kabupaten Kebumen, Jawa Tengah, Tahun 2006. Makara, Kesehatan, 10(2)

Stanley, M. \& Beare, P. G., 2006. Buku ajar keperawatan gerontik. 2 ed.Translated from English by N. Juniarti.Jakarta: EGC.

Udjianti, W.J., 2010. Keperawatan Kardiovaskular. Jakarta: Salemba Medika

WHO., 2007. WHO global report on falls prevention in older age. Geneva : WHO Press. 